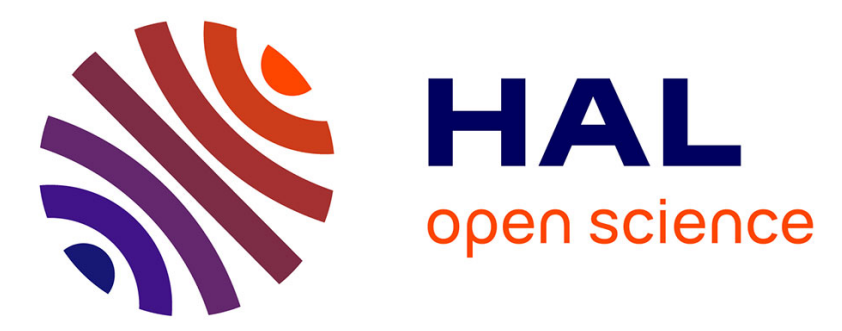

\title{
Discrete element modelling of concrete structures under hard impact by ogive-nose steel projectiles
}

Andria Antoniou, Laurent Daudeville, Philippe Maurice Marin, Ahmad Omar, Serguei Potapov

\section{- To cite this version:}

Andria Antoniou, Laurent Daudeville, Philippe Maurice Marin, Ahmad Omar, Serguei Potapov. Discrete element modelling of concrete structures under hard impact by ogive-nose steel projectiles. The European Physical Journal. Special Topics, 2018, 227 (1-2), pp.143-154. hal-02002070

\section{HAL Id: hal-02002070 https://hal.univ-grenoble-alpes.fr/hal-02002070}

Submitted on 31 Jan 2019

HAL is a multi-disciplinary open access archive for the deposit and dissemination of scientific research documents, whether they are published or not. The documents may come from teaching and research institutions in France or abroad, or from public or private research centers.
L'archive ouverte pluridisciplinaire $\mathbf{H A L}$, est destinée au dépôt et à la diffusion de documents scientifiques de niveau recherche, publiés ou non, émanant des établissements d'enseignement et de recherche français ou étrangers, des laboratoires publics ou privés. 


\title{
Discrete element modelling of concrete structures under hard impact by ogive-nose steel projectiles
}

\author{
Andria Antoniou ${ }^{1, *}$, Laurent Daudeville ${ }^{1}$, Philippe Marin ${ }^{1}$, Ahmad Omar $^{1,2}$ and Serguei Potapov ${ }^{3}$ \\ ${ }^{1}$ Université Grenoble Alpes, CNRS, Grenoble INP, 3SR, 38000 Grenoble, France \\ ${ }^{2}$ AZM university, Tripoli, Lebanon \\ ${ }^{3}$ IMSIA EDF-CNRS-CEA-ENSTA UMR 9219, 91762 Palaiseau, France
}

\begin{abstract}
Concrete structures are widely used as shielding barriers to protect sensitive infrastructures. Accidental conditions such as aircraft impacts on nuclear containments lead to a designing demand under extreme loadings. A discrete element method (DEM) model is presented, able to predict damage of concrete structures under severe impacts. The original developments of Cundall and Strack for granular materials were extended in the proposed DEM model for cohesive materials such as concrete by introducing cohesive interactions in addition to contact ones. Spring-like interactions between discrete elements are based on phenomenological models inspired by observations at the macroscopic scale. Constitutive parameters are calibrated thanks to simulations of experiments performed under different states of loading (unconfined quasi-static tests, high confined compression, high strain rates). The DEM approach is validated with the simulation of three hard impact tests where numerical and experimental results are discussed. CEA Gramat performed the experiments on plain concrete targets with a passive confinement given by a steel jacket surrounding the cylindrical specimen and submitted to the impact of ogive-nosed steel projectiles.
\end{abstract}

\section{Introduction}

The increasing demand for infrastructure security requires accounting for the severe dynamic loading due to natural or manmade hazards, such as aircraft impacts. Because of the extreme severity of such a loading, assessment of the protective structures must go far beyond verification of the resistance to normal operating conditions: it is necessary to investigate the response of the structure until almost its complete failure to assess correctly its ultimate resistance capacity.

While continuous approaches such as the finite element method (FEM) are suitable for the nonlinear analysis of structures before failure, they reach their limits when trying to describe macro cracking and fragmentation mechanisms. The discrete element method (DEM) is a powerful alternative to FEM when advanced damage states and failure of concrete have to be studied. Indeed, DEM allows easily obtaining realistic macrocrack patterns and material fragments due to its ability to represent discontinuities.

In previous papers, a coupled DEM-FEM approach was proposed to deal with soft impact on RC structures $[1,2]$. This paper presents a DEM approach able to predict the response of concrete structures under severe loading such as hard impact, for instance due to the turbine of an aircraft engine. The discrete elements (DE) are spheres of different sizes and masses; they do not represent the constituents of concrete such as aggregates. Spheres are chosen to easily handle the contact interactions between DE at the macroscopic scale.

The links between DE are modelled thanks to beam-like elements with a non-linear constitutive phenomenological model aiming at reproducing damage and compaction (closure of porosity) of concrete at the macroscopic scale. The increase of strength with strain rate is taken into account in tension. The proposed numerical method is validated with the simulation of three hard impact tests conducted by CEA Gramat [3-4]. Ogive-nose steel projectiles were launched on plain concrete targets and generated penetration or perforation. The DE simulations of these tests are discussed. All the numerical developments were made in EUROPLEXUS [5], a finite element (FE) software for the simulation of fast dynamics phenomena coownership of CEA and European Commission (Joint Research Center).

\section{Discrete element model}

The DEM was originally developed to model granular materials such as sand by Cundall and Strack [6, 7]. Afterwards, different authors extended this method to cohesive materials such as concrete, by taking into 
account cohesive interactions in addition to contact ones [8-12].

In the proposed method, the concrete (or RC concrete) structure is modelled by a disordered polydisperse assembly of rigid spherical elements with different sizes and masses obtained thanks to a geometric algorithm based on a tetrahedral FE mesh [13] (Fig. 1).

The method is based on a special disordering technique of non-overlapping spheres that allows filling a given tetrahedral FE mesh. This algorithm was implemented in SherePadder++ [14] free software, which was introduced into the open-source SALOME platform [15]. The DE model aims at reproducing the macroscopic constitutive behaviour of concrete. Thus, the DE packing is required to be isotropic, which can be evaluated from the projection of the interactions' orientations.

\subsection{Definition of interactions}

An interaction is defined between two spheres $a$ and $b$ of radii $R_{a}$ and $R_{b}$ respectively inside an interaction range, which is determined by an interaction coefficient $\lambda$ (Fig. 2). The two types of links (contact and cohesive) are grouped and treated by equation (1), where $\mathrm{D}_{a, b}$ is the distance between the centroids of the elements $a$ and $b$ with $\lambda \geq 1$.

$$
\lambda\left(\mathrm{R}_{\mathrm{a}}+\mathrm{R}_{\mathrm{b}}\right) \geq \mathrm{D}_{\mathrm{a}, \mathrm{b}}
$$

A contact interaction is possible, when the distance between two DE particles is less than or equal to the sum of their radii $(\lambda=1)$. In contrast, cohesive interactions exist even when the elements are not in contact $(\lambda>1)$; a cohesive link allows transmitting tensile forces contrarily to contact links that transmit forces in compression only.

For each element, the number of links with its neighbours varies with the value of $\lambda$. The desired number of interactions can be set by adjusting the interaction coefficient $\lambda$. This defines $N$, the average number of interactions per discrete element (2). An average number $N=12$ links per $\mathrm{DE}$ was selected by Rousseau [16] to model concrete as an isotropic and homogeneous material.

$$
\mathrm{N}=\frac{\text { number of links }}{\text { number of DE }}
$$

Prior to the simulation a list of interacting elements is created for each DE. Once a link is broken or a new contact is detected, this list is updated. At each time step and for each DE, the resulting force is calculated thanks to the list of interacting elements.
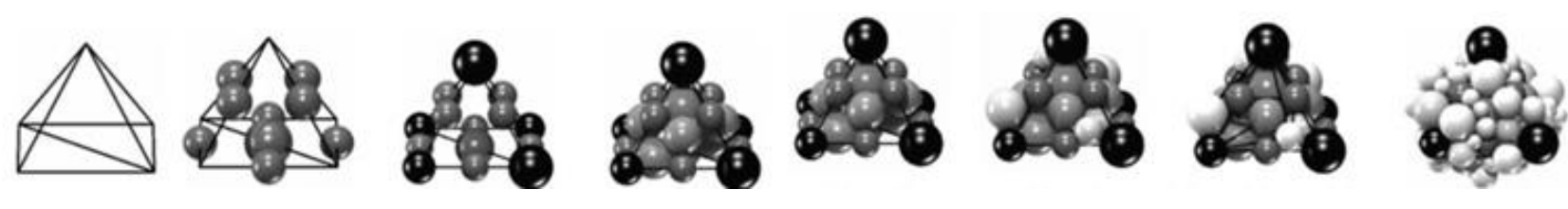

Fig. 1: DE assembly technique
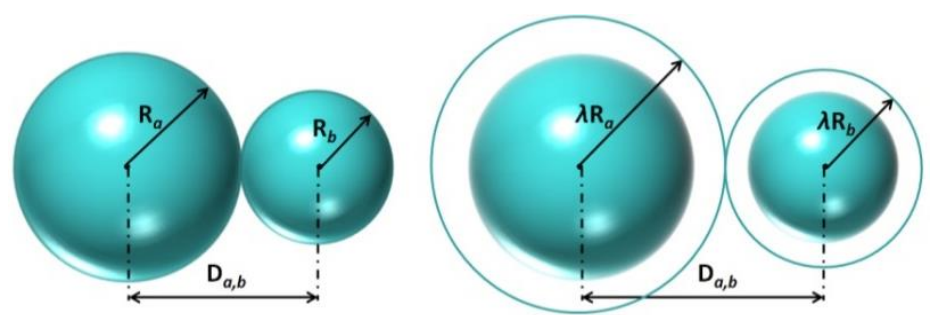

Fig.2: Contact and cohesive interactions

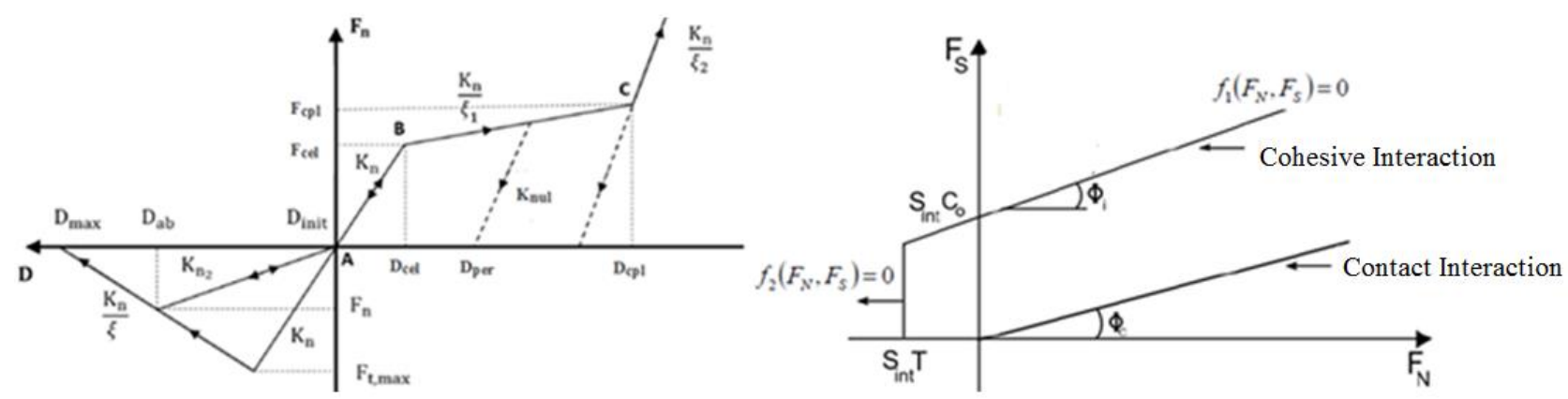

Fig. 3: Non-linear constitutive behaviour, Normal force - Displacement (left), Tangential force - Normal force (right) 


\subsection{Constitutive behaviour of discrete element concrete model}

Undamaged plain concrete is considered to be isotropic, homogeneous and linear elastic at the macroscale, whereas after micro cracking the behaviour becomes non-linear. Concrete's behaviour is modelled at the microscale by means of two types of interactions whose behaviour is inspired by the phenomenological behaviour observed at the macroscale. Contact links can create only contractive forces whereas cohesive links can receive also tensile forces. Two spheres in interaction are related at an equivalent contact point with spring-like links. The elastic behaviour of concrete is described by means of macro-micro relations proposed by Donzé et al. [8] and used in several studies [1-2, 9-12, 16]. A third rolling spring-like interaction associated to a rolling stiffness $\mathrm{K}_{R}$ has been implemented by Omar et al. [17] in order to offer a rolling resistance preventing from brittle failure. A modified Mohr-Coulomb criterion is used for the modelling of non-linear behaviour $[10,18]$.

\subsection{Linear elastic constitutive behaviour}

For the elastic behaviour, macro-micro relations are used to deduce the local normal $K_{N}$ and tangential $K_{S}$ stiffnesses from the macroscopic elastic properties, Young's modulus E, and Poisson's ratio v. These relations are originated from Voigt's hypothesis [19] and the best fit hypothesis [20] used for regular assemblies. Those approximations have been modified by Donzé et al. [8] to take into account the disordered assemblies and the size of the interactive elements. Equations (3) show the micro-macro relations between two elements $a$ and $b$. $\mathrm{D}_{\text {init }}^{a, b}$ represents the initial distance between two elements, with radius $\mathrm{R}_{a}$ and $\mathrm{R}_{b}$ and $\mathrm{S}_{\text {int }}$ is the interaction surface. Young's modulus $E$, and Poisson's ratio $v$ are considered as the input values of the model from which $\alpha, \beta$ and $\gamma$ parameters need to be identified by means of quasi-static compression and tension tests.

$$
\begin{gathered}
\mathrm{K}_{N}=\frac{E \mathrm{~S}_{\text {int }}}{\mathrm{D}_{\text {init }}^{a, b}} \frac{1+\alpha}{\beta(1+v)+\gamma(1-\alpha v)} \\
\mathrm{K}_{S}=\mathrm{K}_{N} \frac{1-\alpha v}{1+v}
\end{gathered}
$$

The identification procedure of the linear elastic behaviour parameters $\alpha, \beta$ and $\gamma$ is described in [10]. A compression test on ordinary concrete with the macroscopic parameters $E=25 \mathrm{GPa}$ and $v=0.16$ performed by Gabet et al. [21, 22] was simulated and the parameters were calibrated, $\alpha=3.9, \beta=3.75$ and $\gamma=5$.

\subsection{Non-linear constitutive behaviour}

The non-linear constitutive behaviour of concrete cohesive link between two discrete elements $a$ and $b$ is characterized by a local criterion of rupture found in several studies [1, 2, 8-12, 16]. A modified Mohr-
Coulomb criterion with a sliding function $f_{l}$ and a tensile rupture criterion $f_{2}$ is used for cohesive links (4).

$$
\begin{gathered}
\mathrm{f}_{1}\left(\mathrm{~F}_{\mathrm{N}}, \mathrm{F}_{\mathrm{S}}\right)=\left|\mathrm{F}_{\mathrm{S}}\right|-\tan \left(\Phi_{\mathrm{i}}\right) \mathrm{F}_{\mathrm{N}}-\mathrm{S}_{\mathrm{int}} \mathrm{C}_{\mathrm{o}} \\
(\text { a. Shear sliding function }) \\
\mathrm{f}_{2}\left(\mathrm{~F}_{\mathrm{N}}, \mathrm{F}_{\mathrm{S}}\right)=-\mathrm{S}_{\text {int }} \mathrm{T}-\mathrm{F}_{\mathrm{N}} \\
(\text { b. Tensile damage function })
\end{gathered}
$$

Parameters of the non-linear constitutive behaviour are a friction angle $\Phi_{i}$, a cohesion stress $C_{0}$, a local tensile cut off stress $T$ and a softening factor $\xi$ (Fig. 3).

The damage criterion (4b) is activated if the normal displacement between two elements $a$ and $b$ is greater than the displacement associated to the local tensile strength $F_{\text {tmax }}$. Beyond this displacement, the link is into the softening regime where the normal stiffness is defined as $\frac{K_{N}}{\xi}$; it is limited to a maximum distance $D_{\max }$. Once two spheres come in contact, a new contact interaction is created, which follows a classical MohrCoulomb criterion with a contact angle $\Phi_{\mathrm{c}}(5)$.

$$
\mathrm{f}_{1}\left(\mathrm{~F}_{\mathrm{N}}, \mathrm{F}_{\mathrm{S}}\right)=\left|\mathrm{F}_{\mathrm{S}}\right|-\tan \left(\Phi_{\mathrm{C}}\right) \mathrm{F}_{\mathrm{N}}
$$

The criterion of contact interactions is expressed as:

$f_{I} \leq 0$, the contact link is opposed to interpenetration $f_{l}=0$, the shear force follows the sliding function

The compressive non-linear plastic behaviour is governed by the compaction phenomenon, which occurs under high confinement. Once the elastic limit $F_{c e l}=$ $\sigma_{c e l} \mathrm{~S}_{\text {int }}$ is exceeded, the pore closure leads to a plastic regime until the plastic limit $F_{c p l}=\sigma_{c p l} \mathrm{~S}_{\text {int }}$, where consolidation takes place, after the collapse of porosity, with a hardening branch. The stiffness of each branch is defined as the ratio of the initial stiffness of the link $K_{N}$ over the parameters $\xi_{1}$ and $\xi_{2}$ respectively.

Fig. 3 presents the two models, on the right is plotted the sliding functions, while on the left is illustrated the local link's behaviour in the normal direction (of the two centroids). The parameters of the model are identified thanks to simulation of quasi-static tests in tension and unconfined compression. The compaction law parameters are identified through inverse modelling of oedometric compression (one-dimensional deformation) whereas hydrostatic compression tests performed thanks to a triaxial device that allows applying triaxial compression tests on concrete with a confining pressure $p$ up to $650 \mathrm{MPa}$ [21-24] (Fig. 4).
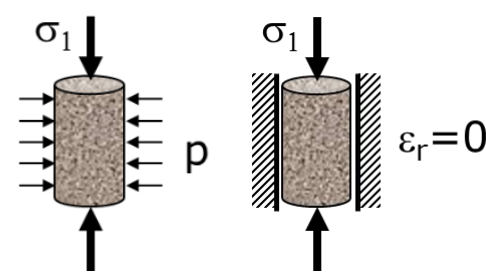

Fig. 4: Hydrostatic $\left(\sigma_{1}=p\right)$ and oedometric compression tests 

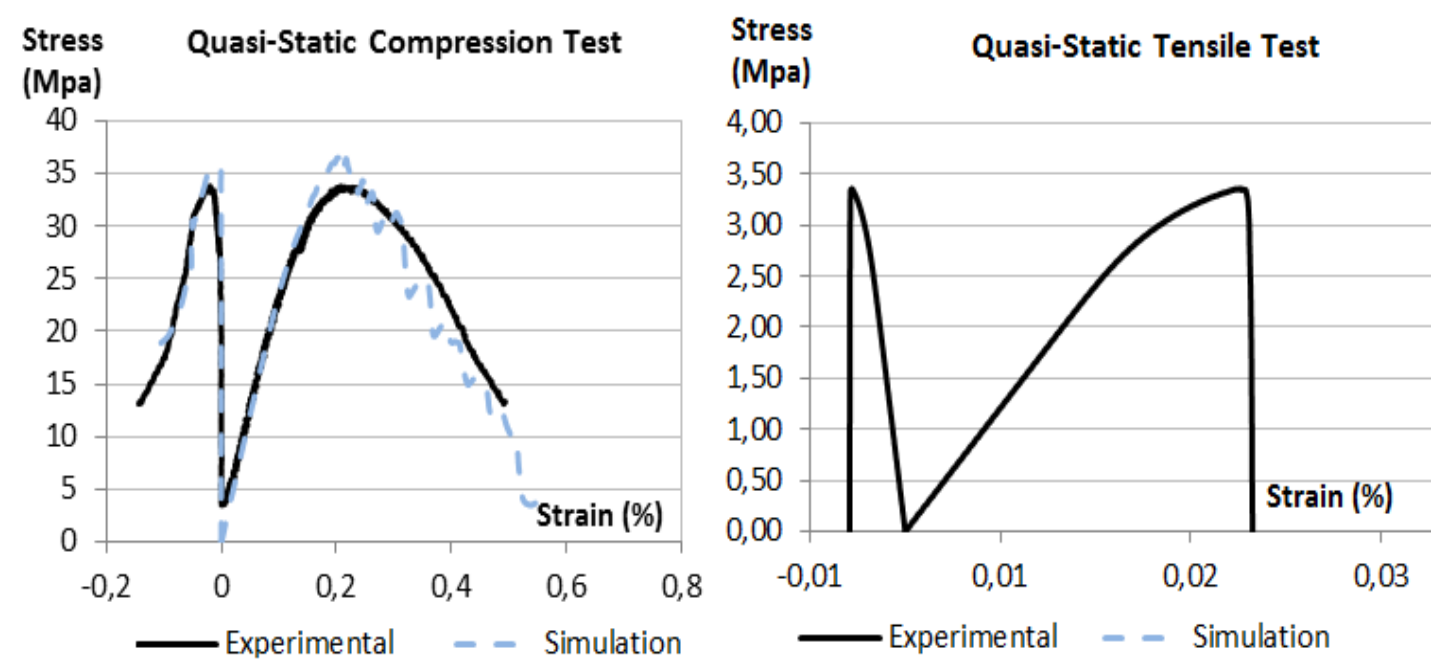

Fig. 5: Simulation of quasi-static unconfined tests
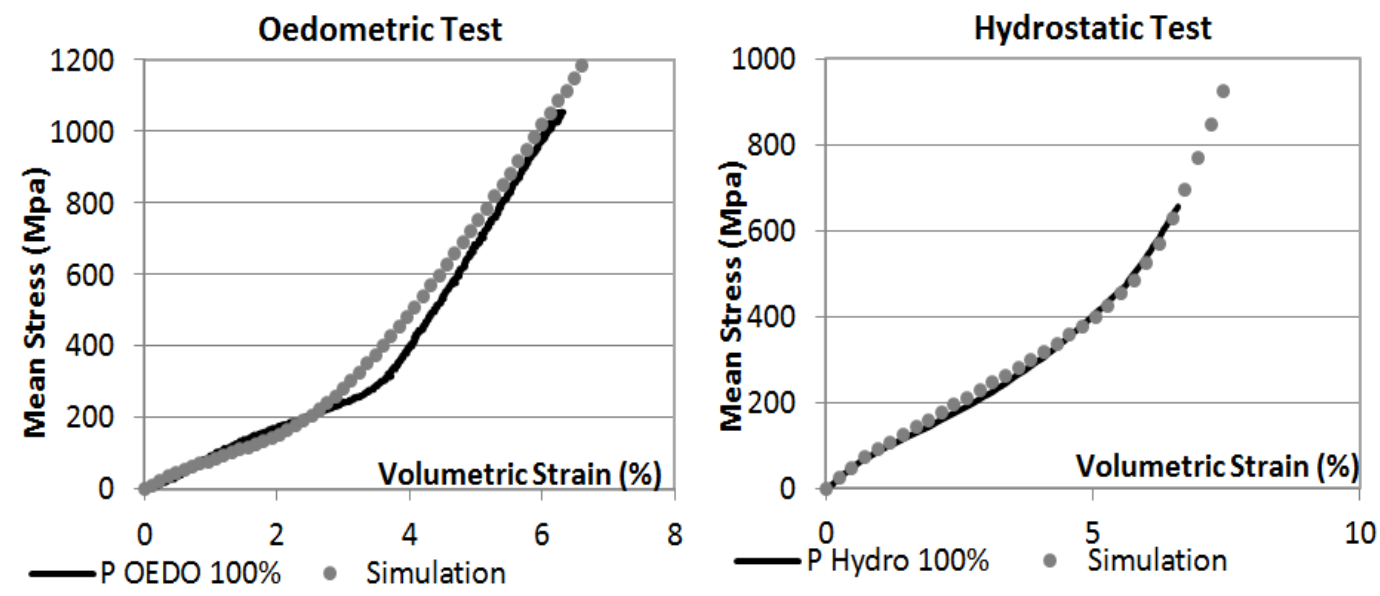

Fig. 6: Simulation of high confining pressure tests

The non-linear behaviour parameters under low confining pressure were identified as $\mathrm{C}_{0}=3.5 \mathrm{MPa}$, $\mathrm{T}=3 \mathrm{MPa}, \xi=3, \varphi_{\mathrm{i}}=30^{\circ}$ and $\varphi_{\mathrm{c}}=30^{\circ}$ by modelling quasi-static tensile and compressive tests with macroscopic strengths $\sigma_{\mathrm{c}}=34 \mathrm{MPa}$ and $\sigma_{\mathrm{T}}=3.4 \mathrm{MPa}$ respectively (Fig. 5). The parameters referred to high confining pressures were identified from simulations of hydrostatic and oedometric tests (Fig. 6) as $\sigma_{c e l}=50 \mathrm{MPa}, \sigma_{c p l}=300 \mathrm{MPa}, \xi_{1}=1.5$ and $\xi_{2}=0.3$.

\subsection{Strain rate dependency}

It has been observed that both the tensile and compressive strengths of concrete-like materials increase with strain-rate, especially when the strain-rate is greater than a transition strain-rate, which is around $10^{0}-10^{1} \mathrm{~s}^{-1}$ for uniaxial tension and $10^{2} \mathrm{~s}^{-1}$ for uniaxial compression, respectively. However, it has been found that the strainrate enhancement of the compressive strength of concrete-like materials [25] is largely caused by the introduction of radial confinement in split Hopkinson pressure bar (SHPB) tests [26-30], which cannot be simply interpreted as material behaviour. Brace and Jones [31] first explained that the compressive strength

increase can be due to the change of stress state from uniaxial stress to uniaxial strain under increasing radial confinement.

In addition, in a very interesting paper by G. Cusatis [32], the author demonstrates that for strain rates higher than $10^{-1} \mathrm{~s}^{-1}$ the inertia forces cannot be neglected and provide a significant contribution to the strength enhancement recorded during experiments. He also shows that taking into account inertia forces thanks to a 3D transient dynamics model allows describing most of the strain rate effect observed in uniaxial compression whereas it is necessary to include a strain-rate dependency in the micro-level model in order to describe correctly the observed strain rate effect in uniaxial tension.

Thus, the authors decided to introduce the strain rate dependency in the phenomenological DEM model in tension only. This pragmatic choice allows a simple identification of the dynamic increase factor (DIF) through an inverse analysis based on the dynamic numerical simulation of Hopkinson bar spalling tests.

The strain rate dependency implemented in DEM is inspired by the CEB formula [33] to calculate the macroscopic dynamic compressive and tensile strengths as function of strain rate (6). 
DIF is defined as the ratio of the dynamic tensile strength over the static tensile strength $T_{d y n} / T_{s t}$. Due to the lack of available experimental data related to the specific fracture energy at high strain rates, it is assumed that the increase is applied also on the maximum distance limit $D_{\max }$, as can be seen on Fig. 7. The local parameters $\varepsilon_{s t}^{\cdot}, \delta_{1}$ and $\delta_{2}$ are calibrated with the help of a Hopkinson bar spalling test [34]. The experimental pullback velocity of the specimen's rear face, is reproduced with the parameters $\varepsilon_{s t}^{\cdot}=10^{-6}, \delta_{l}=0.052$ and $\delta_{2}=0.333$.

$$
\mathrm{DIF}=\frac{\mathrm{T}_{\mathrm{dyn}}}{\mathrm{T}_{\mathrm{st}}}=\left\{\begin{array}{cl}
1 & \text { if } \dot{\varepsilon} \leq \varepsilon_{\mathrm{st}} \\
\left(\frac{\dot{\varepsilon}}{\dot{\varepsilon_{\mathrm{st}}}}\right)^{\delta 1} & \text { if } \varepsilon_{\mathrm{st}}^{\cdot}<\dot{\varepsilon} \leq 1 \mathrm{~s}^{-1} \\
\theta\left(\frac{\dot{\varepsilon}}{\dot{\varepsilon}_{\mathrm{st}}}\right)^{\delta 2}, \theta=10^{(6 \delta 1-2)} & \text { if } \dot{\varepsilon}>1 \mathrm{~s}^{-1}
\end{array}\right.
$$

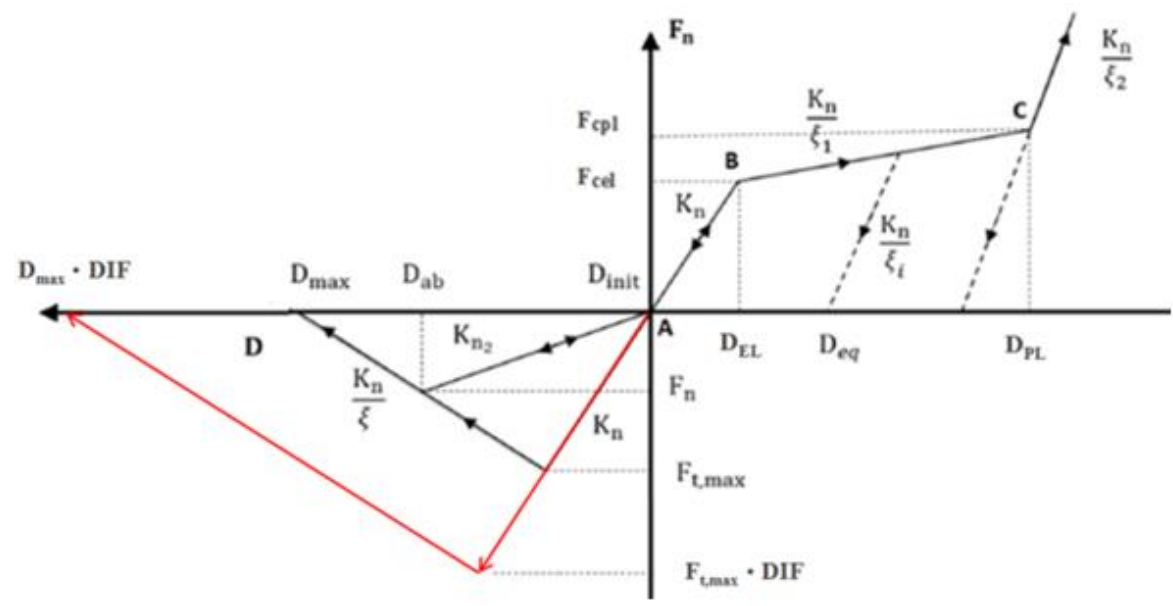

Fig. 7: Constitutive model under dynamic loading

\section{Simulation of impacts}

The reliability of the proposed DEM numerical model is validated with the simulation of high velocity impacts on confined concrete. The numerical results are compared with the experimental data obtained by CEA Gramat.

\subsection{Impact experiments}

A series of impact tests have been performed by CEAGramat [3-4] with a gas launcher and ogive-nosed steel projectiles with a nose radius to diameter ratio of 5.77 , a $52.06 \mathrm{~mm}$ shank diameter, a $299.43 \mathrm{~mm}$ length and a $2.442 \mathrm{~kg}$ mass (Fig. 8). Targets were made of fully saturated unreinforced R30A7 ordinary concrete confined with a thin steel jacket. R30A7 concrete was widely investigated in previous studies [21-24]. The target diameter is $800 \mathrm{~mm}$, while the thickness is 300 $\mathrm{mm}$ for the perforation test and $800 \mathrm{~mm}$ for the two penetration tests. The confined steel jacket has a $15 \mathrm{~mm}$ thickness and it is fixed to the concrete target.

An accelerometer was embedded into the projectile (Fig. 8) to record the axial deceleration during the experiment and to obtain both displacement and velocity by integration. The correct integration of the acceleration was validated by the comparison of the integrated and measured projectile velocities by means of a laser technique.

After the test a topographic system was used to measure the crater dimension and the penetration depth. Three tests have been conducted with different striking velocities, one perforation test at $333 \mathrm{~m} / \mathrm{s}$ and two perforation tests at high velocity ( $\mathrm{HV}, 347.4 \mathrm{~m} / \mathrm{s})$ and low velocity (LV, $227 \mathrm{~m} / \mathrm{s})$. Fig. 9 shows the damage mode at different stages of the perforation test and the two faces of the target after the HV penetration test. 

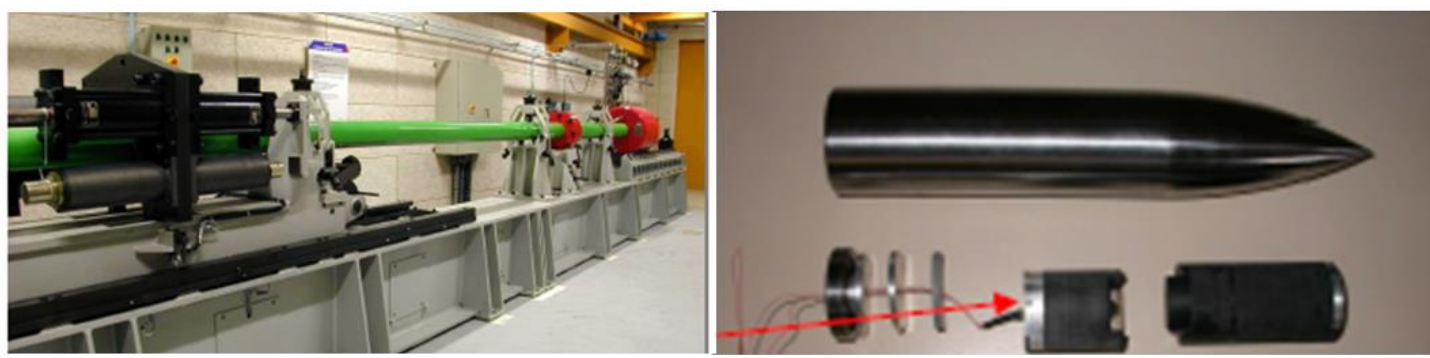

Fig. 8: Gas launcher (left), projectile with its accelerometer (right)

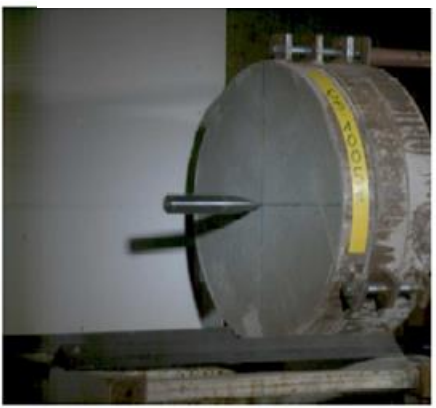

$\mathrm{T}=0 \mathrm{~ms}$

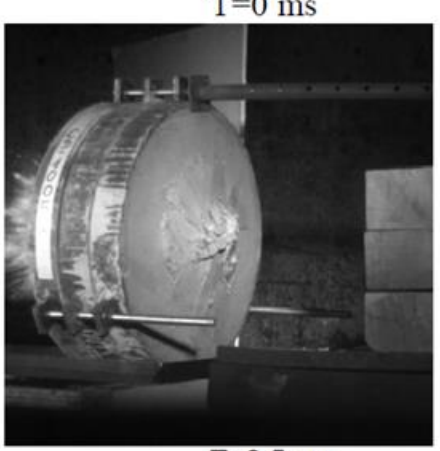

$\mathrm{T}=2.5 \mathrm{~ms}$

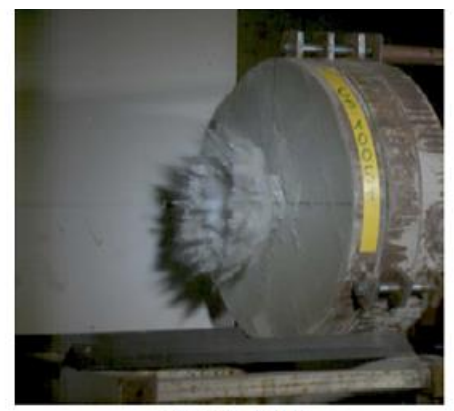

$\mathrm{T}=2.5 \mathrm{~ms}$

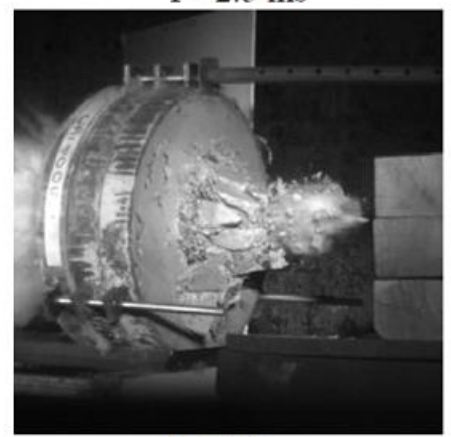

$\mathrm{T}=8 \mathrm{~ms}$
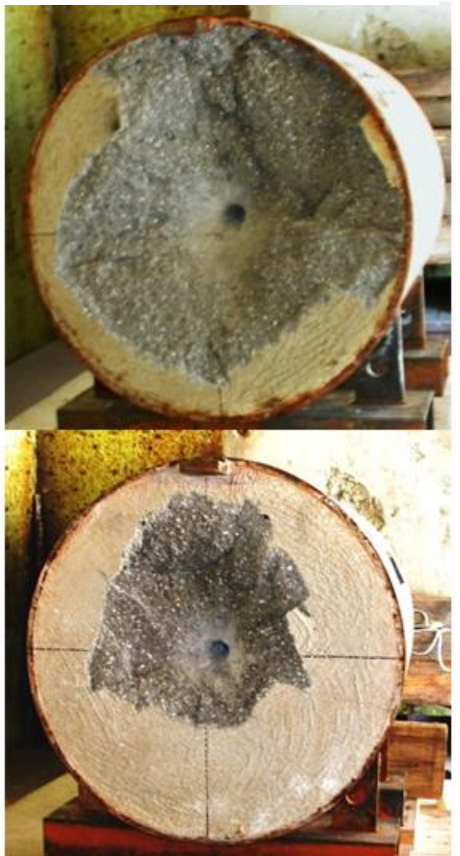

Fig. 9: Impact tests - perforation (left), penetration (right)

\subsection{Modelling of impact experiments}

The cylindrical concrete specimen was modelled with DE, while tetrahedral FE were used for the steel projectile and the steel confining jacket (Fig. 10). The DE packing was created from a tetrahedral FE mesh thanks to SherePadder++ [14] direct geometrical algorithm. Sizes of FE tetrahedra were selected in order to produce spheres with diameters similar to the FE sizes of the projectile and of the steel jacket for a proper management of contact between FE and DE. Table 1 illustrates the DE properties of the perforation and penetration tests. Furthermore, for the simulations of the three impact experiments $10 \%$ of damping was used.

Fig. 11 shows the numerical and experimental results for the perforation impact test. On the left side is plotted the axial displacement of the projectile while on the right side its velocity. The right side of Fig. 12 presents the crack pattern observed after the perforation test to be compared with the damage state obtained from the numerical simulation on the left side. Fig. 13 and Fig. 14 present the same results for the HV penetration test.
The numerical results are in good accordance with the experimental ones. For the perforation test the results

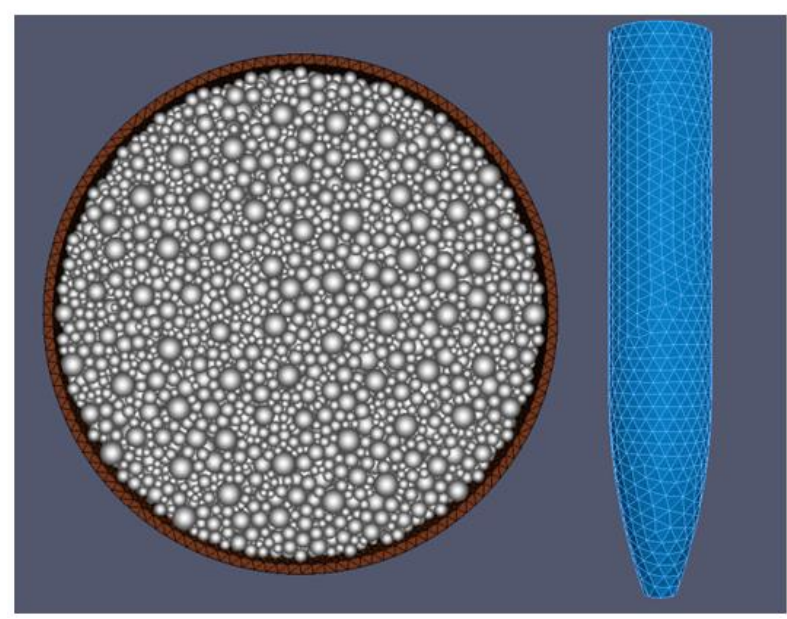

Fig. 10: Left - DE model of concrete target concrete with FE confining steel jacket (300 mm diameter)

Right - FE steel projectile (52.06 mm diameter, $299.43 \mathrm{~mm}$ length) 
are thoroughly matched. However, a slight difference is observed on the curves of the penetration tests. The damage for both experiments seems to be quite similarly produced by the DE model, with more significant diagonal cracks at the bottom of the perforated specimen than the top. In addition, by comparing Fig. 9 (right) with Fig. 14 (left), it is obvious that the phenomena observed experimentally, such as spalling on the front and scabbing on the rear face, have been successfully generated during the perforation test simulation. Furthermore, a cratering damage mode is observed in the penetration test that was also reproduced in numerical results.

Table 1: Properties of perforation and penetration DE discretizations

\begin{tabular}{|l|c|c|c|c|c|c|}
\hline & Compactness & $\mathrm{DE} \#$ & $\lambda$ & $\mathrm{R}_{\max }(\mathrm{cm})$ & $\mathrm{R}_{\min }(\mathrm{cm})$ & $\mathrm{R}_{\operatorname{mean}}(\mathrm{cm})$ \\
\hline Perforation & 0.6086 & 141765 & 1.3986 & 0.9 & 0.3 & 0.471 \\
\hline Penetration & 0.6154 & 336467 & 1.402 & 0.9384 & 0.3128 & 0.491 \\
\hline
\end{tabular}
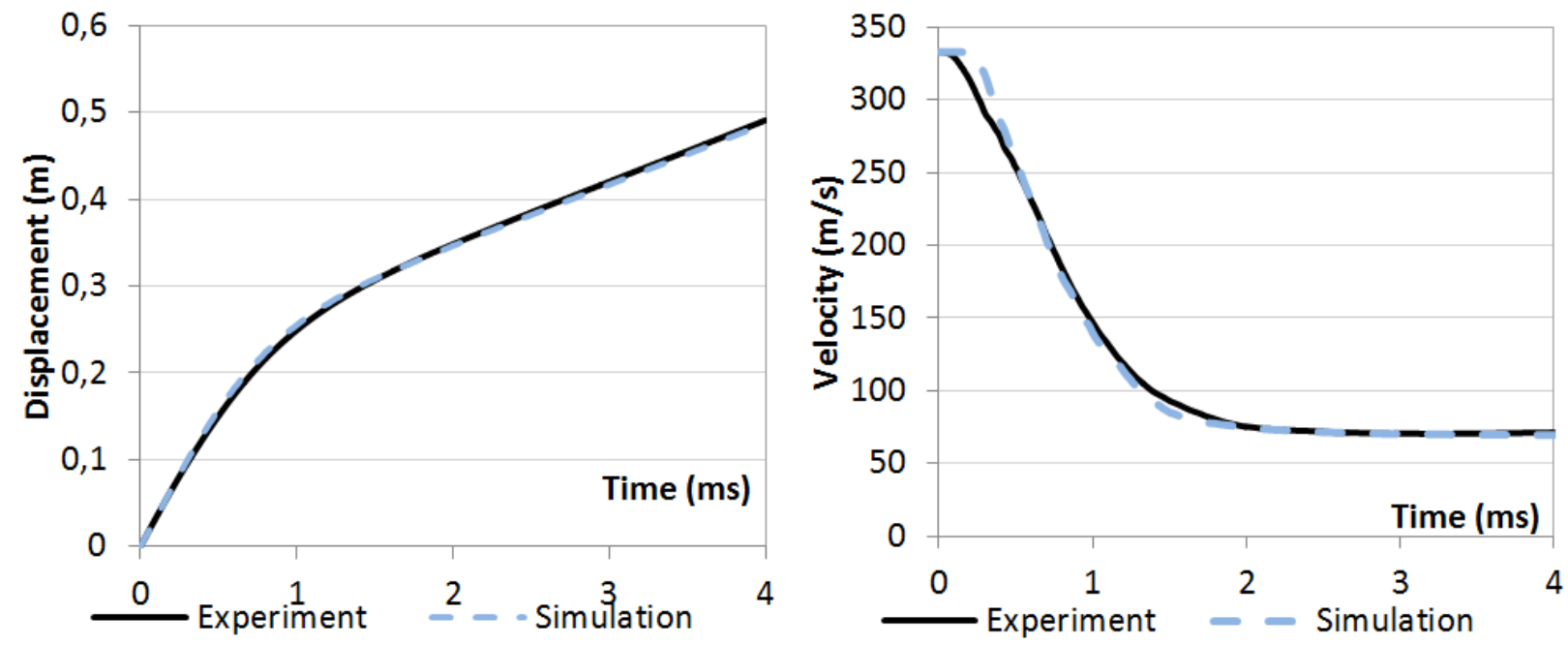

Fig. 11: Perforation test, simulation and experiment, projectiles axial displacement (left), velocity (right)
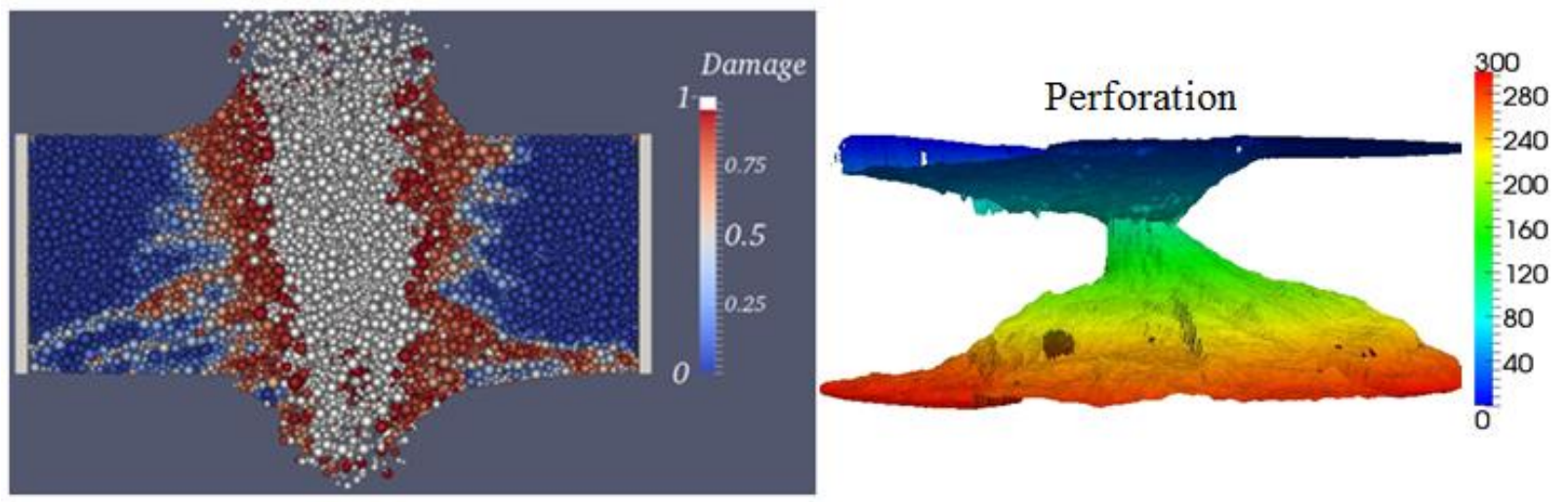

Fig. 12: Perforation crack pattern, simulation (left) and experiment (right) 


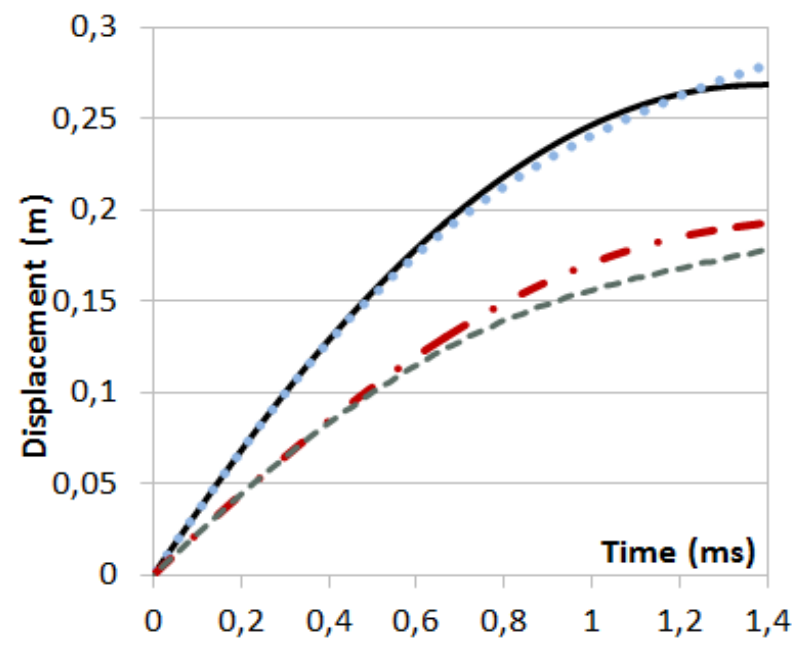

- Experiment HV $\ldots .$. Simulation HV

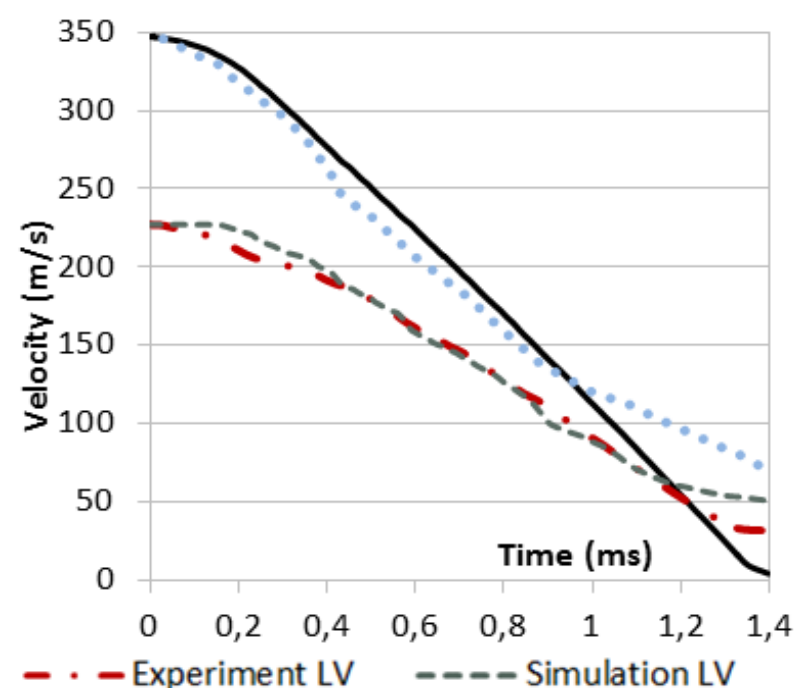

- - - Experiment LV -----Simulation LV

Fig. 13: Penetration test, simulation and experiment, projectile axial displacement (left), velocity (right)
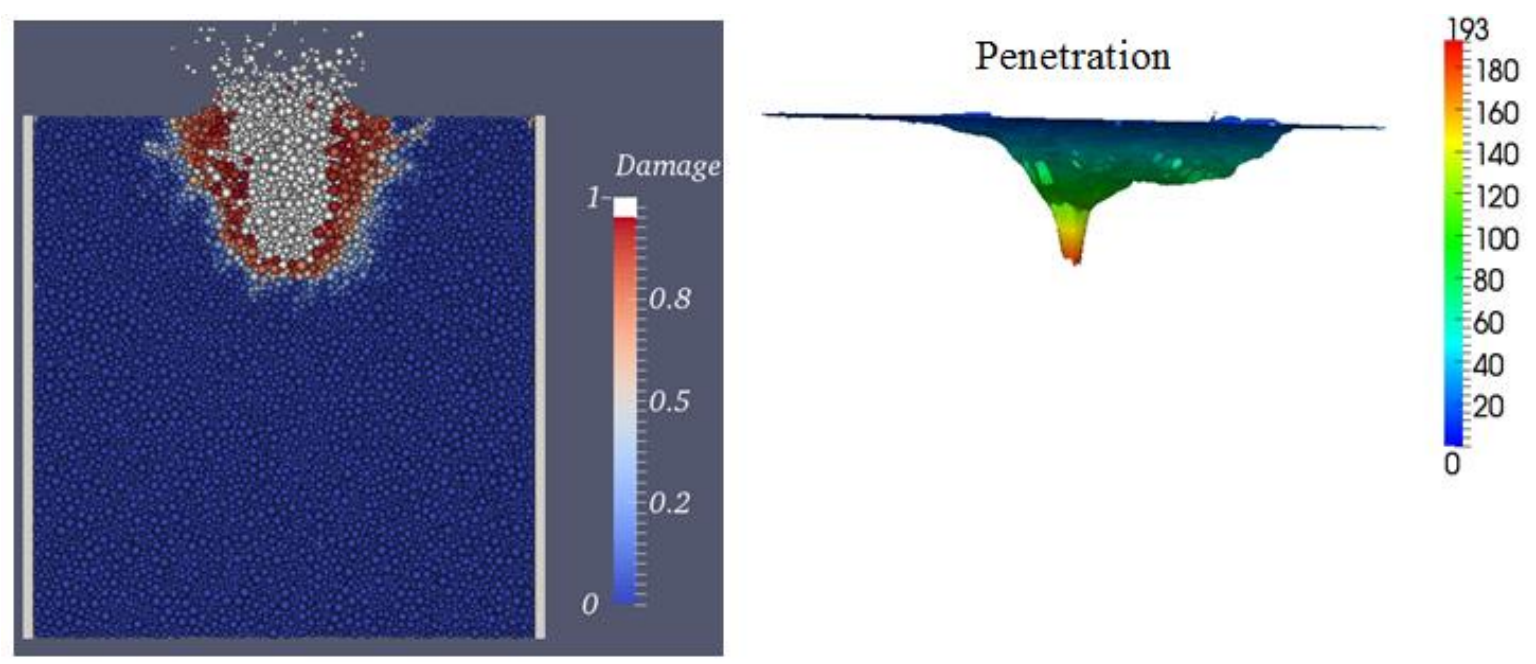

Fig. 14: HV Penetration crack pattern, simulation (left) experiment (right)

\section{Conclusion}

In this paper a numerical model of DEM for concrete was proposed to model a structure under severe loadings. The DEM approach was applied to simulate impact experiments on thick confined concrete specimen, which can represent an aircraft engine impact on a RC shielding. Perforation and penetration tests were satisfactorily reproduced by the model. The crack patterns are in good accordance with the experimental ones. This study gives the motivation to start in simulating the response of industrial-size concrete structures.

\section{Acknowledgements}

This research has been developed with the financial support of the Centre d'études de Gramat (CEG, CEA DAM) and EDF. We would like to thank Dr. Christophe
Pontiroli (CEG) for giving technical and scientific advice.

\section{Author contribution statement}

This research was carried out during Andria Antoniou's $\mathrm{PhD}$ supervised by other authors. All authors contributed equally to the paper.

\section{References}

1. S. Potapov, A. Masurel, P. Marin, L. Daudeville, J. Eng. Mech., 143(2), 04016110 (2016)

2. E. Frangin, P. Marin, L. Daudeville, J. Phys. IV. 134, 461-466 (2006)

3. C. Pontiroli, B. Erzar, E. Buzaud, Concrete behaviour under ballistic impacts: Effects of materials parameters to penetration resistance and modeling with PRM model. In Proceedings of 
Computational Modeling of Concrete Structures, St Anton am Arlberg, ed. CRC Press (2014)

4. H. Bian, Y. Jia, J. Shao, C. Pontiroli, Eng. Struct., 111, 525-537 (2016)

5. EUROPLEXUS, A computer program for analysis of fast transient phenomena involving structures and fluids in interaction, http://www-epx.cea.fr

6. P.A. Cundall, O.D.L. Strack, Geotechnique, 29(1), 47-65 (1979)

7. P.A. Cundall, Int. J. Rock Mech. and Mining Sc., 25, 107-116 (1988)

8. F. Donzé, S.A. Magnier, L. Daudeville, C. Mariotti, L. Davenne, J. Eng. Mech. 125(10), 1154-63 (1999)

9. W. Shiu, F. Donzé, L. Daudeville, Computers and Structures. 86(21-22), 2079-86 (2008)

10. S. Hentz, L. Daudeville, F. Donzé, J. Eng. Mech., 130 (6), 709-719 (2004).

11. S. Hentz, L. Daudeville, F.V. Donzé, Comp. and Struct. 82(29-30), 2509-24 (2004)

12. L. Daudeville, Y. Malecot, Eur. J. of Env. and Civil Eng. 15(S1), 101-140 (2011)

13. J. Jerier, D. Imbault, F. Donzé, P. Doremus, Granular Matter, 11, 43-52 (2009)

14. SherePadder++, Computer software, https://subversion.assembla.com/svn/spherepadder

15. SALOME, Computer software, http://www.salomeplatform.org

16. J. Rousseau, E. Frangin, P. Marin, L. Daudeville, Computers and Concrete, 5(4), 343-358 (2008)

17. A. Omar, P. Marin, S. Potapov, L. Daudeville, 3D discrete element modeling of concrete: Study of the rolling resistance effects on the macroscopic constitutive behavior, in Proceedings of XII International conference on Computational Plasticity-Fundamentals and Applications, COMPLAS XII Barcelona (2013)

18. Y. Sazamoto, H. Tsubota, Y. Kasai, N. Kishiba, H. Morikawa, Nuclear Engineering and Design, 179, 157-177 (1998)

19. B. Cambou, P. Dubujet, F. Emeriault, F. Sidoroff, Homogenization for granular materials. Eur. J. Mech. A Solids, 14(2), 255-276 (1995).

20. C.L. Liao, T.P. Chang, D.H. Young, C.S. Chang, Int. J. Solids Struct., 34(31-32), 4087-4100 (1997)

21. T. Gabet T., Y. Malécot, L. Daudeville, Cement and Concrete Res., 38(3), 403-412 (2008)

22. T. Gabet, X.H. Vu, Y. Malécot, L. Daudeville, J. Phys IV, 134, 635-640 (2006)

23. X.H. Vu, Y. Malecot, L. Daudeville, J. of Strain Analysis for Eng. Design, 44(8), 633-657 (2009)

24. Y. Malecot, L. Daudeville, F. Dupray, C. Poinard, E. Buzaud, Eur. J. of Env. and Civil Eng. 14(6-7), 777-803 (2010)

25. P.H. Bischoff, S.H. Perry, Mater. Struct., 24, 425-50 (1991)
26. Q.M. Li, H. Meng, Int. J. Solids Struct., 40, 343-60 (2003)

27. X.Q. Zhou, H. Hao, Int. J. Solids Struct., 45, 4648 $61(2008)$

28. M. Zhang, H.J. Wu, Q.M. Li, F.L. Huang, Int. J. Impact Eng., 36, 1327-34 (2009)

29. Q.M. Li, Y.B. Lu, H. Meng, Int. J. Impact Eng., 36 , 1335-45 (2009)

30. D.J. Kim, K. Sirijaroonchai, S.E. El-Tawil, A. Naaman, Int. J. Impact Eng., 37, 141-9 (2010)

31. W.F. Brace, A.H. Jones, Comparison of uniaxial deformation in shock and static loading of three rocks. J. Geophys. Res. 76, 4913-21 (1971)

32. G. Cusatis, Strain-rate effects on concrete behaviour, Int. J. Impact Eng., 38, 162-170 (2011)

33. CEB-FIP model code 1990. Comité Eurointernational du Béton. Ed. Thomas Telford (1993)

34. A. Antoniou, Contribution to the experimental analysis and numerical modelling of spalling technique into concrete specimens under dynamic tension. Master thesis, Université Joseph Fourier (2014) 